\title{
Economics of milk production in Pune district of Maharashtra: A comparative analysis
}

\author{
Athare PG ${ }^{1}$, Ajay Verma ${ }^{2}$, R Malhotra ${ }^{3}$ and Sendhil R $^{4}$
}

Received: 19 July 2019 / Accepted: 21 September 2019 / Published online: 31 December 2019

(C) Indian Dairy Association (India) 2019

\begin{abstract}
The study of economics of milk production is an important base to determine the profitability of dairy farming. The information was collected from 80 members and 80 nonmembers of dairy cooperatives from Pune district of Maharashtra in 2018-19. The average net maintenance cost per animal per day was more for members as compared to non-members in case of crossbred and local cow, where as in case of buffalo it was more for non-members as compared to members. Per litre cost of milk production for crossbred cow, buffalo and local cow was observed more for member group as compared to non-member group. The feed and fodder accounted major share in total variable cost followed by labour cost for both group. Further, it was found the return per litre from milk production was more for members as compared to non-members in case of crossbred cow. Whereas in case of buffalo, return per litre from milk production was more for non-members than members due to non-members are selling milk directly to the consumers and getting more price. In case of local cow, net return per litre of milk production worked out to be negative for both members and non-members due to low productivity and there is need increase the productivity by adopting scientific dairy farming practices.
\end{abstract}

Athare $\mathrm{PG}^{1}$, Ajay Verma ${ }^{2}$, R Malhotra ${ }^{1}$ and Sendhil $\mathrm{R}^{2}$

${ }^{1}$ Division of Dairy Economics, Statistics and Management, ICAR-National Dairy Research Institute, Karnal-132001, Haryana, India

${ }^{2}$ ICAR- Indian Institute of Wheat and Barley Research, Karnal-132 001, Haryana, India

Athare PG $(\bowtie)$

Division of Dairy Economics, Statistics and Management, ICAR-National

Dairy Research Institute, Karnal-132001, Haryana, India

Email:prakashathare121@gmail.com
Keywords: Capital recovery cost, Dairy cooperatives, Net return and average cost, Standard animal unit,

\section{Introduction}

The livestock sector is considered as an integral part of Indian agriculture. Among various agricultural enterprises common household maintains livestock as a complementary activity to supplement their income and nutritional requirement of family. Considering the vagaries of the monsoon and its adverse effect on crop production, dairy farming is emerging as a major source of income as well as for employment and it has broader social and economic dimension. Dairy cooperatives have played a significant role in the production, marketing and processing of milk and their products (Candler and Kumar, 1998) thereby it contributing towards livelihood security of the millions of the milk producers in the country (Singh and Pundir, 2000). Besides realization of better price paid by consumers, the areas in which cooperative network provides input or resource services to the dairy farmers and farmers are benefited in terms of better yield of dairy animal, more employment opportunities among member households as compared to non-members. Hence the study on economic analysis of milk production of member and nonmembers are gaining more importance to identify the difference between them. The cost of milk production is an important tool for the evaluation of economics of dairy enterprise at producers' level as well as for fixing the procurement price at Dairy Cooperative Society level, thereby ensures that producers get remunerative price for milk and consumers get milk and milk products at reasonable price. The objective of the present study is to analyze the cost and returns of milk production across different herd size and compare between members and nonmembers.

\section{Materials and Methods}

\section{Selection of the study area}

Maharashtra state has been purposively selected to conduct the study. Maharashtra is a one of the leading in the country as far as dairying is concerned. According to $19^{\text {th }}$ Livestock Census2012 , Maharashtra ranked $6^{\text {th }}$ in total livestock population. The 
total bovine population was reported to be 21.07 million in the state which comprised of 3.65 millions of crossbred cow, 11.83 millions of indigenous cow and 5.59 millions of buffalo. Maharashtra ranks $7^{\text {th }}$ in total milk production with 11.10 million tonnes next to Uttar Pradesh, Rajasthan, Madhya Pradesh, Andhra Pradesh, Gujarat and Punjab. The State also ranks third in total number of dairy cooperative societies with 20,647 and it creates competitive environment for milk procurement, processing and marketing with private milk marketing channel. The Pune is an India's one of the metropolitan city it leads to high demand for milk and milk product that also influences milk production. It is the $2^{\text {nd }}$ largest milk producing district in the state with milk production of 11188.71 lakh litre during 2015-16 after Ahmednagar. The numbers of dairy cooperative societies in the district are 1108 which is third highest in the state after Kolhapur (3937) and Solapur (1827).

\section{Data collection}

There are 14 blocks in the district out of which 2 blocks namely Baramati and Ambegaon were selected randomly for present study. The Primary data for present investigation was collected from members and non-members of dairy cooperative societies(DCS) on detailed information about age of household head, family size and its composition and education level of household head, details of inventory of bovine kept and their particulars, farm inventory, feed storage structure, dairy equipments, quantity of green fodder and concentrate fed to each animal, mode of procurement, procurement price, labour use (hired and family) in different activity, prevailing wage rate, veterinary and miscellaneous expenses, milk production, disposal and utilization pattern of milk, price of milk received per litre of milk by the milk producers. The data was collected from 80 members and 80 non-members by using structured and semistructured interview schedule and cumulative square root frequency method was used for post stratification of sample households into small, medium and large herd size category.

\section{Analytical framework}

To achieve the objectives of the study, the data was scrutinized, compiled, tabulated and analyzed by employing the following analytical tools. The analytical tools used for analysis of data are discussed in the present sections

\section{Tabular analysis}

We applied the tabular analysis to work out cost and return from milk production, size of operational land holding and area under fodder crops across different herd size category for member and non-members households.

\section{Cost of milk production}

The cost and return of milk production is an important concern for dairy enterprise in order to get idea about whether the dairy enterprises are getting profit or not and it is an indicator of economic efficiency of milk production. The various cost components were identified as fixed cost and variable cost. These costs are discussed briefly in this section.

\section{Fixed costs}

Fixed costs do not vary with the level of output and remain unchanged over a short period of time. The various components of fixed cost are depreciation and interest on fixed capital. Capital Recovery Cost method was used to calculate depreciation. The cost item interest on fixed capital does not need to be accounted for separately when CRC approach is followed.

\section{Depreciation costs}

It is the loss in the value of an asset due to normal wear and tear, time and technological obsolescence. It can be accounted by using the Capital Recovery Cost (CRC) Method. The CRC method is defined as the annual payment that will repay the cost of fixed input over the useful life of input and provide an economic rate of return on investment. The formula for estimation of CRC is:

$$
\mathrm{R}=\mathrm{Z}\left[\frac{(1+\mathrm{r})^{\mathrm{n}} \mathrm{r}}{(1+\mathrm{r})^{\mathrm{n}}-1}\right]
$$

where,

$\mathrm{R}=$ Capital recovery cost

$\mathrm{Z}=$ Initial value of the capital asset

$\mathrm{r}=$ Interest rate

$\mathrm{n}=$ Useful life of the assets

In case of practical difficulties in getting the information on initial outlay at the field level, the current value of asset was considered. When the asset was purchased from borrowed capital the actual interest rate charged by the bank was taken as ' $r$ ', while in case of owned funds, the interest on term deposit of 1-5 years was taken. The useful life of assets was assumed to be 50 years for pucca cattle shed, 20 years for katcha shed, 6 years for manual chaff cutter, 10 years for power operated chaff cutter. The useful life of milch animals also varied with the type of animal and was taken as 10, 8 and 10 years for local cow, crossbred cow and buffalo, respectively. The total CRC was then apportioned to the individual animal in accordance with the Standard Animal Units (SAUs).

\section{Variable cost}


Variable costs are those costs, which are incurred on the variable factors of production and can be altered in the short run. Variable cost includes three items i.e. feed and fodder cost, labour cost and veterinary and miscellaneous expenditure.

\section{Feed and fodder cost}

This included the cost of feeding green fodder, dry fodder and concentrates to animals. In case of purchased feed and fodder, the cost was worked out as product of quantity fed to animal and purchase price of respective feed. In case of home-grown feed and fodder, the relevant prices were the farm-harvest prices. For certain types of fodder, especially cultivated green fodder, where farm-harvest prices were not available, the imputed value of crop is worked out and taken as the prevailing price of standing crop in the village. In case the animal was fed with collected grass and tree leaves from the common property resources, its imputed value was their expected sale price and was accounted for while estimating the cost. When the concentrate feed was prepared at home, its cost was computed by taking the weighted prices of ingredients used in the concentrate, the weights being the share of each ingredient in the concentrate composition.

\section{Labour cost}

The information on total time spend for doing various operations on farm were collected from farmers. Total time spent was converted to man days by using conversion as: men)

1 day of women labour $=0.67$ man day $(3$ women $=2$

1 day of child labour $=0.50$ man day $(2$ child $=1$ men $)$ by assuming 8 working hours a day.

The cost of grazing of animals was also included in labour cost.

\section{Veterinary and miscellaneous costs}

The expenditure on breeding and health care of the animals was covered under the veterinary expense. It included, cost of artificial insemination (AI), natural service, vaccination, medicines, fee of veterinary doctor and other related expenses. The miscellaneous expenditure included expenses on repair of fixed assets, water and electricity charges, insurance premium and any other incidental charges. These being joint costs, apportionment of the same based on SAU were done.

\section{Apportionment of joint costs}

Among the various cost items discussed, certain expenses are incurred on the entire herd as a whole. For instance, the fixed assets like cattle shed, stores, mangers, water tub, buckets etc., are jointly used by the entire herd. Also, the information on cost on labour and miscellaneous items were not available animal wise but for the entire herd as a whole. Therefore, for the apportionment of these joint costs the total number of animal were converted into standard animal units.

\section{Regional Standard Animal Units (SAUs)}

Considering the differences in regional endowments of animal wealth and species, the SAUs have been formulated by Sirohi et al. (2015) at regional level for five regions viz; Eastern (including north-east), Western, Southern, Northern plains and Hills. Most of the earlier studies have considered only labour utilization as the basis of apportionment. In this case, apart from labour utilization, the body weight of the animal was also taken into consideration for the estimation of the SAUs. Based on expert opinion 60 per cent weight was given to labour utilization and 40 per cent to body weights of animals for the final estimation. As the study area falls in the Western region so Standard Animal Units (SAU) for this region was used as given in table 1.

\section{Other cost concepts used}

\section{Gross cost}

It was obtained by adding all the cost components including fixed and variable costs, i.e.

$$
\text { Gross cost }=\text { Total variable cost }+ \text { Total fixed cost }
$$

\section{Net cost}

The net cost was worked out by deducting the imputed income earned through dung, from the gross cost.

$$
\text { Net cost }=\text { Gross cost “ Value of dung }
$$

\section{Gross returns}

Gross returns were obtained by multiplying milk yield of an individual milch animal with respective prevailing prices in the study area

Gross returns $=$ Quantity of milk $\times$ Market price of milk

\section{Net returns}

Net return was calculated by subtracting net cost from gross returns

$$
\text { Net returns }=\text { Gross returns }- \text { Net cost }
$$

\section{Results and Discussion}

This section of the paper gives a brief idea about economics of milk production separately for members and non-members across different herd size category for crossbred cow, buffalo and local 
cow. Similarly, the composition of various cost components in gross cost and per litre return from milk production was also discussed. While calculating the cost of milk production the main component comprises fixed and variable cost. Variable cost has higher share in the average cost of milk production. The feed and fodder accounted major share in total variable cost. Returns from milk production are obtained by selling milk and milk products and disposing dung as manure.

The table 2 indicates overall average net maintenance cost per day per animal was found more for members in comparison to non-members i.e. '202.49 and '200.17, respectively as also

Table1 Standard Animal Units for Western Regions of India

\begin{tabular}{lllc}
\hline \multicolumn{1}{c}{ Animals } & Crossbred cow & Local Cow & Buffalo \\
\hline Adult Male (e"3 years) & 0.87 & 0.72 & 0.82 \\
Adult Female (e"3 years) & 1.18 & 1.00 & 1.22 \\
Young Stock Male ( $<$ 1 year) & 0.39 & 0.36 & 0.40 \\
Young Stock Female (<1 year) & 0.37 & 0.35 & 0.38 \\
Young Stock Male $(>1$ year) & 0.55 & 0.40 & 0.46 \\
Young Stock Female ( $>$ 1 year) & 0.42 & 0.38 & 0.42 \\
$\quad$ Heifers & 0.71 & 0.40 & 0.63 \\
\hline
\end{tabular}

(Source: Sirohi et al. 2015)

Table 2 Average Cost and Returns from Milk Production for Crossbred Milch Cow ('/Animal/Day)

\begin{tabular}{|c|c|c|c|c|c|c|c|c|}
\hline \multirow[t]{2}{*}{ Cost Components } & \multirow{2}{*}{$\frac{\text { Small }}{\mathrm{M}}$} & \multicolumn{3}{|c|}{ Medium } & \multirow{2}{*}{$\frac{\text { Large }}{\mathrm{M}}$} & \multicolumn{3}{|c|}{ Overall } \\
\hline & & NM & M & NM & & NM & M & NM \\
\hline $\begin{array}{l}\text { Total Fixed Assets } \\
\text { (TFC) }\end{array}$ & $\begin{array}{l}37.96 \\
(18.46)\end{array}$ & $\begin{array}{l}35.08 \\
(17.27)\end{array}$ & $\begin{array}{c}38.12 \\
(18.17)\end{array}$ & $\begin{array}{c}34.79 \\
(16.62)\end{array}$ & $\begin{array}{c}40.52 \\
(18.80)\end{array}$ & $\begin{array}{c}37.63 \\
(17.64)\end{array}$ & $\begin{array}{c}38.39 \\
(18.43)\end{array}$ & $\begin{array}{c}35.27 \\
(17.15)\end{array}$ \\
\hline $\begin{array}{c}\text { Green Fodder } \\
\text { (F1) }\end{array}$ & $\begin{array}{c}44.91 \\
(35.86)\end{array}$ & $\begin{array}{c}45.96 \\
(34.64)\end{array}$ & $\begin{array}{l}45.56 \\
(33.18)\end{array}$ & $\begin{array}{c}47.35 \\
(32.51)\end{array}$ & $\begin{array}{c}44.57 \\
(30.65)\end{array}$ & $\begin{array}{c}46.30 \\
(31.20)\end{array}$ & $\begin{array}{c}45.05 \\
(34.19)\end{array}$ & $\begin{array}{c}46.32 \\
(33.73)\end{array}$ \\
\hline $\begin{array}{l}\text { Dry Fodder } \\
\text { (F2) }\end{array}$ & $\begin{array}{l}18.06 \\
(14.42)\end{array}$ & $\begin{array}{l}22.40 \\
(16.88)\end{array}$ & $\begin{array}{c}25.34 \\
(18.45)\end{array}$ & $\begin{array}{c}27.62 \\
(18.97)\end{array}$ & $\begin{array}{l}30.04 \\
(20.66)\end{array}$ & $\begin{array}{l}27.26 \\
(18.37)\end{array}$ & $\begin{array}{l}21.95 \\
(16.66)\end{array}$ & $\begin{array}{l}24.13 \\
(17.57)\end{array}$ \\
\hline $\begin{array}{l}\text { Concentrate } \\
\text { (F3) }\end{array}$ & $\begin{array}{c}62.28 \\
(49.72)\end{array}$ & $\begin{array}{c}64.32 \\
(48.48)\end{array}$ & $\begin{array}{c}66.42 \\
(48.37)\end{array}$ & $\begin{array}{c}70.68 \\
(48.53)\end{array}$ & $\begin{array}{c}70.81 \\
(48.69)\end{array}$ & $\begin{array}{l}74.86 \\
(50.44)\end{array}$ & $\begin{array}{c}64.75 \\
(49.15)\end{array}$ & $\begin{array}{c}66.89 \\
(48.70)\end{array}$ \\
\hline $\begin{array}{l}\text { Feed \& Fodder Cost } \\
\quad(\mathrm{V} 1=\mathrm{F} 1+\mathrm{F} 2+\mathrm{F} 3)\end{array}$ & $\begin{array}{l}125.25 \\
(74.68)\end{array}$ & $\begin{array}{l}132.68 \\
(78.92)\end{array}$ & $\begin{array}{l}137.31 \\
(80.02)\end{array}$ & $\begin{array}{l}145.65 \\
(83.46)\end{array}$ & $\begin{array}{l}145.42 \\
(83.12)\end{array}$ & $\begin{array}{l}148.42 \\
(84.45)\end{array}$ & $\begin{array}{l}131.75 \\
(77.53)\end{array}$ & $\begin{array}{l}137.34 \\
(80.60)\end{array}$ \\
\hline $\begin{array}{l}\text { Labour Cost } \\
\text { (V2) }\end{array}$ & $\begin{array}{c}34.69 \\
(20.68)\end{array}$ & $\begin{array}{c}29.36 \\
(17.47)\end{array}$ & $\begin{array}{c}28.89 \\
(16.83)\end{array}$ & $\begin{array}{c}23.54 \\
(13.49)\end{array}$ & $\begin{array}{c}24.23 \\
(13.85)\end{array}$ & $\begin{array}{c}21.45 \\
(12.20)\end{array}$ & $\begin{array}{c}31.45 \\
(18.51)\end{array}$ & $\begin{array}{c}27.19 \\
(15.96)\end{array}$ \\
\hline $\begin{array}{l}\text { Miscellaneous Cost } \\
\text { (V3) }\end{array}$ & $\begin{array}{c}7.79 \\
(4.64)\end{array}$ & $\begin{array}{l}6.07 \\
(3.61)\end{array}$ & $\begin{array}{c}5.41 \\
(3.15)\end{array}$ & $\begin{array}{l}5.32 \\
3.05\end{array}$ & $\begin{array}{c}5.30 \\
(3.03)\end{array}$ & $\begin{array}{c}5.88 \\
(3.35)\end{array}$ & $\begin{array}{l}6.73 \\
(3.96)\end{array}$ & $\begin{array}{c}5.87 \\
(3.45)\end{array}$ \\
\hline $\begin{array}{l}\text { Total Variable Cost } \\
(\mathrm{TVC}=\mathrm{V} 1+\mathrm{V} 2+\mathrm{V} 3)\end{array}$ & $\begin{array}{l}167.73 \\
(81.54)\end{array}$ & $\begin{array}{l}168.11 \\
(82.73)\end{array}$ & $\begin{array}{l}171.61 \\
(81.83)\end{array}$ & $\begin{array}{l}174.50 \\
(83.38)\end{array}$ & $\begin{array}{l}174.95 \\
(81.20)\end{array}$ & $\begin{array}{l}175.75 \\
(82.36)\end{array}$ & $\begin{array}{l}169.93 \\
(81.57)\end{array}$ & $\begin{array}{l}170.39 \\
(82.85)\end{array}$ \\
\hline $\begin{array}{c}\text { Gross Cost } \\
(\mathrm{A}=\mathrm{TFC}+\mathrm{TVC})\end{array}$ & $\begin{array}{c}205.69 \\
(100.00)\end{array}$ & $\begin{array}{c}203.20 \\
(100.00)\end{array}$ & $\begin{array}{c}209.73 \\
(100.00)\end{array}$ & $\begin{array}{c}209.30 \\
(100.00)\end{array}$ & $\begin{array}{c}215.47 \\
(100.00)\end{array}$ & $\begin{array}{c}213.38 \\
(100.00)\end{array}$ & $\begin{array}{c}208.32 \\
(100.00)\end{array}$ & $\begin{array}{c}205.66 \\
(100.00)\end{array}$ \\
\hline Value of Dung (B) & 5.88 & 5.56 & 5.66 & 5.31 & 5.98 & 5.52 & 5.83 & 5.49 \\
\hline $\operatorname{Net} \operatorname{Cost}(C=A-B)$ & 199.81 & 197.64 & 204.07 & 203.99 & 209.49 & 207.87 & 202.49 & 200.17 \\
\hline Price of milk & 24.30 & 23.59 & 24.54 & 24.00 & 25.20 & 24.52 & 24.51 & 23.78 \\
\hline $\begin{array}{l}\text { Average milk production } \\
\text { /animal/day (E) }\end{array}$ & 9.12 & 8.83 & 9.79 & 9.34 & 10.80 & 10.05 & 9.56 & 9.08 \\
\hline Gross Return (D) & 221.54 & 208.44 & 240.39 & 224.10 & 272.18 & 246.39 & 234.37 & 215.84 \\
\hline Net Return (D-C) & 21.73 & 10.80 & 36.32 & 20.11 & 62.69 & 38.52 & 31.89 & 15.67 \\
\hline Cost/Litre (C/E) & 21.92 & 22.37 & 20.84 & 21.84 & 19.40 & 20.69 & 21.17 & 22.06 \\
\hline Return / litre & 2.38 & 1.22 & 3.71 & 2.15 & 5.80 & 3.83 & 3.33 & 1.73 \\
\hline
\end{tabular}

(Figures in parentheses indicates the percentages with their respective totals, M- Member, NM-Non-member) 
reported by Tanwar et al. 2012. The average maintenance cost increases with increase in herd size and highest for large herd size in comparison to medium and small herd size category for both member and non-member groups. The component wise cost of milk production for overall category has shown that the fixed cost accounted Rs 38.39 in case of member and Rs 35.27 in case of non member while variable cost was found Rs 169.93 and '170.39 for members and non-members, respectively. The share of fixed cost and variable cost was 18.43 and 81.57 percent of gross cost, respectively for member group, while for non member group it was 17.15 and 82.85 per cent of gross cost, respectively.

The share of feed and fodder cost to total variable cost increases with increase in herd size for both groups. While, highest was found for non-members ( 80.60 per cent) as compared to members (77.53 per cent) for overall category as also reported by Kumari (2016).The labour cost had decreased with increase in herd size and it was Rs 31.35 and Rs 27.29 for overall category of member and non member groups, respectively. The overall gross return per milch animal in case of members (Rs 234.37) was higher than of non-members (Rs 215.84), while overall net return per milch animal per day was Rs 31.89 and Rs 15.67 for members and nonmembers, respectively. Overall cost per litre of milk production was found lower for members (Rs 22.06) in comparison to nonmembers (Rs 21.17). The cost per litre of milk production decreased with increase in herd size, which were Rs 21.92, Rs 20.84 and Rs 19.40 for small, medium and large herd size category for member group. It ranges from Rs 22.37, Rs 21.84 and Rs 20.69 for small, medium and large herd size category for non-members.

The overall net return per litre of milk production was worked out to be Rs 3.33, while across the herd size categories it was highest for large (Rs 5.80) followed by medium (Rs 3.71) and small (Rs 2.38) herd sizes for member group. Similarly, for non-member farmers overall net return per litre of milk production was Rs 1.73 and it varied from Rs 3.83 for large herd size followed by medium (Rs 2.15) and small (Rs 1.22) herd size category. The present study results shows conformity with the outcomes of earlier

Table 3 Average Cost and Returns from Milk Production for Milch Buffalo (Rs/Animal/Day)

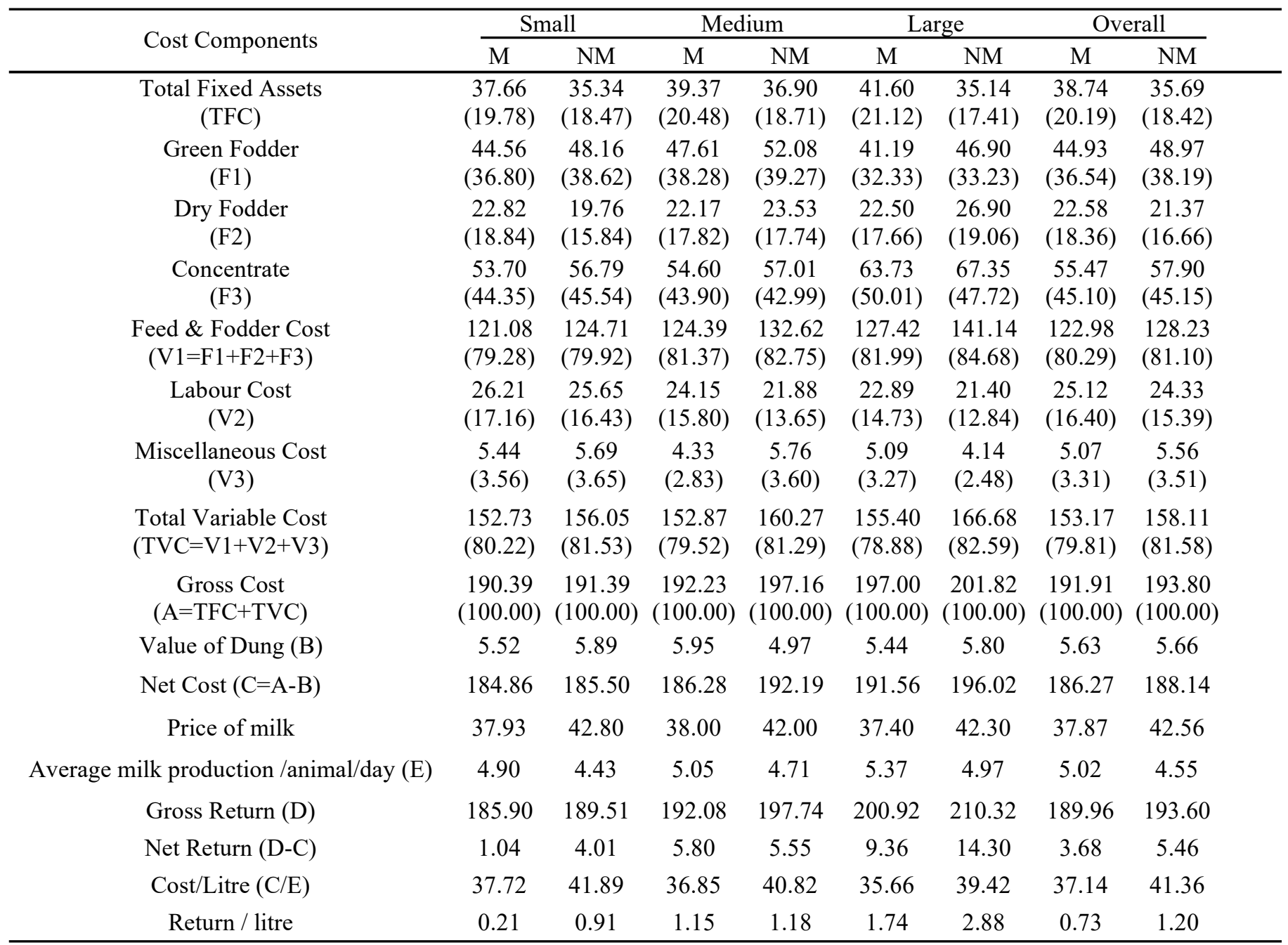

(Figures in parentheses indicates the percentages with their respective totals M- Member, NM-Non-member) 
studies by Priscilla (2017) i.e. Net return per litre of milk production increases with increase in herd size.

Table 3 shows the cost and returns of milk production per milch buffalo per day across the three herd size categories for members and non-members. The average net maintenance cost was more for non-members (Rs 188.14) in comparison with members (Rs 186.27). Across the different herd size category it was highest for large herd size Rs 191.56 than medium (Rs 186.28) and small (Rs 184.86) in case of member group. In case of non-members it ranges from '185.50 (small) to Rs 196.02 (large). The overall fixed cost for members and non-members were Rs 38.74 and Rs 35.69, respectively. The overall total variable cost was found to be Rs 153.17 and Rs 158.11 for members and non-members, respectively. Fixed cost constituted about 20 per cent and variable cost constituted 80 percent for both members and non-members. The feed and fodder comprises major share in total cost of milk production i.e. around 80 per cent followed by labour cost (16 per cent) for both member and non-member group.
The overall gross return per milch buffalo for member group was Rs 189.96 per day. The overall cost per litre of milk production was Rs 37.14 and it decreases with increase in herd size, which were Rs 37.72, Rs 36.85 and Rs 35.66 for small, medium and large herd size category, respectively. The study of Meena et al. (2012) also reported similar observations. The net return per litre of milk production was highest for large herd size at Rs 1.74 followed by medium at Rs 1.15 and small herd size category at Rs 0.21 . While overall return per litre of milk production was Rs 0.73 for member group. The overall gross return per milch buffalo per day for non-member group was Rs 193.60. The overall gross returns per milch buffalo were Rs 189.51, Rs 197.74, and Rs 210.32 for small, medium and large herd size category, respectively. The overall cost per litre of milk production was Rs 41.36 and across the herd size category it ranges from Rs 39.42 (large) to Rs 41.89 (small) herd size group for non-members. It had been found that the net return per litre of milk production increased with increase in herd size category and it was highest for large herd size i.e.Rs2.88 and least for small herd size category at Rs 0.91 for non-members. It

Table 4 Average Cost and Returns from Milk Production for Local Milch Cow (Rs/Animal/Day)

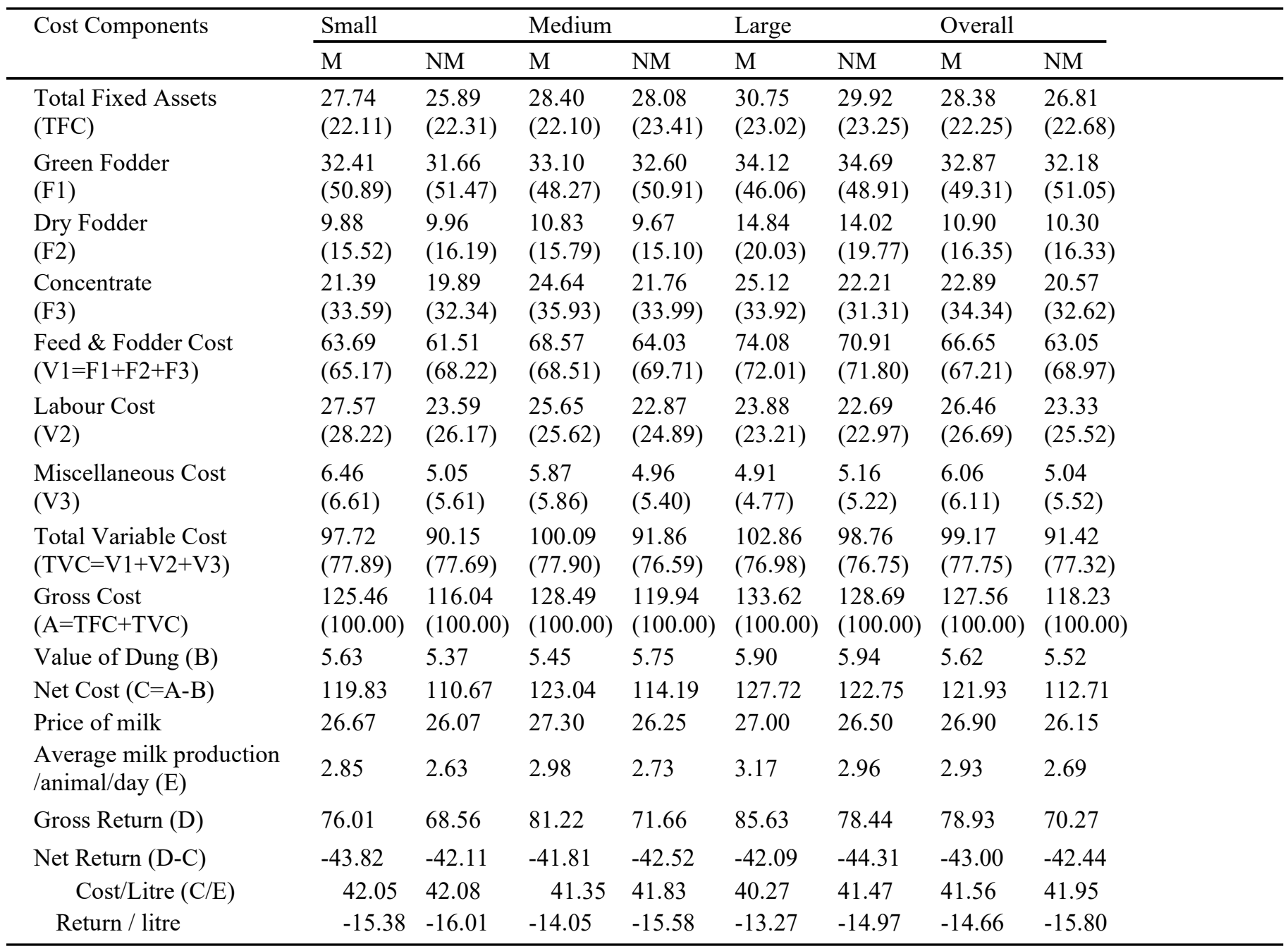

(Figures in parentheses indicates the percentages with their respective totals M- Member, NM-Non-member) 
had been found that the per litre return from milk production was highest for non-member group ('1.20) than that of member group ('0.73). It is not conformity with the earlier studies and it may be due to the non-member were getting higher price by selling milk directly to the consumers.

Table 4 indicates the cost and return from milk production per milch local cow per day. The overall gross maintenance cost for members was more (Rs 127.56) than that of non-members (Rs 118.23). As far as we discuss across the herd size category it was highest for large (Rs 133.62) herd size, followed by medium (Rs 128.49) and small ('125.46) herd size in case of member group. Similarly, in case of non-member farmers it ranges from Rs 116.04 (Small) to '128.69 (large). The component wise break down of total cost of milk production into fixed and variable cost for overall category was found to be Rs 28.38 and Rs 99.17 , respectively for member group. In case of non- member group the fixed and variable cost were Rs 26.81 and Rs 91.42, respectively. The overall cost per litre of milk production was almost same for both member (Rs 41.56) and non-member (Rs 41.95) group. In case of member group the per litre cost of milk production across the herd size category was highest for small farmers (Rs 42.05) and least for large farmers (Rs 40.27). Similarly, for non-member group per litre cost of milk production was highest for small (Rs 42.08) herd size and least for large (Rs 41.56) herd size category.

The overall gross return per milch cow per day was found more for members (Rs 78.93) than that of non-members (Rs 70.27). In case of member group return per litre of milk production for small, medium and large herd size category were Rs -15.38 , Rs-14.05 and Rs-13.27, respectively. Similarly, for non-member farmers the return per litre of milk production was Rs-16.01, Rs-15.58 and '14.47 for small medium and large herd size category, respectively. The overall return per litre of milk production was found to be negative for both member (Rs -14.66) and non-member (Rs-15.80) group and it also shows conformity with previous studies of Sunil et al. (2016) and Nagrale (2017).

\section{Conclusions}

The cost per litre of milk production in case of crossbred cow, buffalo and local cows was found to be decreases across herd sized category, but the net return per milch animal increases with increase in herd size for both member and non-member groups. The return per litre of milk production was highest for member group as compared to non-member group in case of crossbred cow, whereas in case of buffalo the return per litre of milk production was more for non-members than that of members due to the non-member were getting higher price by selling milk directly to the consumers. The study shows that the productivity of local cow is very low in the study area and it leads to negative return from milk production for both members and non-members. Therefore, there is a need to make efforts to increase the productivity of local cows by upgrading the animals and adoption of scientific dairy farming practices and providing more feed and fodder to the animals.

\section{Acknowledgements}

This paper is part of the study conducted for partial fulfillment of the master degree programme in Agricultural Economics of the author from ICAR-National Dairy Research Institute, Karnal, Haryana. The thesis was submitted in 2019 and the title was "Impact of Dairy Cooperatives on the Economy of Rural Households in Pune District of Maharashtra"

\section{References}

Aitawade MS, Bansode RM, Waykar KR, Shinde HR (2005) Economics of Milk Production from Crossbred Cows in Akola district of Maharashtra state. Indian Dairyman 57:48-52

Candler W, Kumar N (1998) The Impact of Dairy Development in India and the World Bank's Contribution. The World Bank Operation Evaluation Department (OED), The World Bank, Washington, D.C.

Kumari B, Malhotra R, Chauhan AK (2016) Impact of woman dairy cooperatives on economics of milk production in Begusarai District of Bihar. Indian J Dairy Sci 69:487-491

Meena GL, Jain DK (2012) Economics of milk production in Alwar district (Rajasthan): A Comparative Analysis. Int J Sci Res Publ 2:1-5

Nagrale GB (2011) Economics of milk production in Vidarbha region of Maharashtra", M.V.Sc Thesis submitted to ICAR-National Dairy Research Institute (Deemed University), Karnal, Haryana.

Priscilla L (2017) Economic analysis of dairy cooperatives in Manipur state", Ph. D. Thesis submitted to ICAR-National Dairy Research Institute (Deemed University), Karnal, Haryana.

Singh K, Pundir RS (2000) Co-operatives and Rural Development in India. Research Paper 17 Institute of Rural Management, Anand

Sirohi S, Bardhan D, Chand P (2015) Cost and return in milk production: Developing standardised methodology and estimates for various production systems, project report of ICAR- National Dairy Research Institute (Deemed University), Karnal submitted to Department of Animal Husbandry, Dairying and Fishery, Ministry of Agriculture and Farmers Welfare, New Delhi.

Sunil VR, BS Chandel, Gururaj M (2016) Economics of milk production in Mandya district of Karnataka. Econ Affairs 61:659-665 